\title{
NO FINER PLACE: PLANNING CORE AREAS IN MID-SIZED CANADIAN CITIES
}

\author{
G. SANDS \\ Wayne State University, USA.
}

\section{ABSTRACT}

In mid-sized urban areas in North America, the downtown core plays a significant role in efforts to sustain and enhance the community. Most core areas of cities in this size range, however, no longer have reputations for being healthy and vibrant. Planners' attempts at downtown revitalization have often been disappointing. Comparison of three highly regarded mid-sized Canadian city centers with three less successful ones leads to the conclusion that there is no unique strategy or combination of public policies sufficient to ensure the success of revitalization efforts. Indeed, some of the more commonly employed strategies appear counter-productive. Planners may have to define a new paradigm of success, if their downtown cores are to contribute to sustainable regions.

Keywords: city planning, downtowns, mid-sized cities, revitalization strategies.

\section{INTRODUCTION}

The concept of a downtown, or central business district, was well established in larger North American urban areas by the end of the nineteenth century [1]. City centers separated commercial activity retail, office, and government - from residential land uses. The dominance of downtown as the Central Business District in the metropolitan area was relatively short lived, however [2]. By the middle of the twentieth century, changes in transportation and communication technologies, along with rising incomes, made low density peripheral development the norm in North American metropolitan areas $[3,4]$. The post-World War II suburban boom created new sources of competition for center city retail and office activities. In most urban areas, it was no longer possible to claim that there was "no finer place' than the city center.

Nevertheless, planners see the downtown core as key to the continued sustainability and vitality of the entire urban area. The city center typically retains important government and economic functions, as well as a high proportion of the property tax base and often employment. It is the focus of the local transportation network and the location of heritage buildings. A vibrant core area can also offer an alternative to new development at the periphery, contributing to the overall sustainability of the urban area.

Over time, planners have shifted their focus from regulation of development and the reduction of congestion in the city center to efforts to ensure that downtown remained competitive with new suburban business centers [5-7]. Attempts to replicate suburban models of development - for example, the introduction of enclosed shopping malls and abundant parking - in the core areas typically have met with only limited success [8,9]. By the 1980s, local governments and private interests adopted new strategies to revitalize city centers, including convention centers, sports venues, and increasing residential populations [10-13]. Other communities promoted entertainment to make their downtown the leading center in the metropolitan area $[14,15]$. The effectiveness of these newer strategies has been, at best, mixed, especially in urban areas with populations between 75,000 and 350,000 [4, 16-19].

This paper examines the effects of city center revitalization strategies on the sustainability of several mid-sized Canadian urban areas. The communities examined include three urban areas that are considered to have successful core areas, along with three that are not as well regarded. In particular, 
those attributes of healthy cores that can be influenced by planning and public policies and thus may provide the basis for developing replicable revitalization strategies are addressed.

\subsection{Identifying successful city centers}

A survey of urban professionals asked about the relative importance of specific attributes of core areas and to identify mid-sized urban areas with successful city centers. The Web-based survey was sent to all identified planning, urban studies, and geography academics and to a sample of local planners and economic development officials in small metropolitan areas [20]. Some 295 surveys were returned, yielding a response rate of just over 34 percent.

Respondents were asked to select (from a list of 19 items) those features of the city center that led them to consider an area to be successful. The following were identified as most important: pedestrian friendly environment, with people on the streets; active, street oriented retail; cultural events; and employment. Green spaces, civic events, tourist activities, historic character, strong neighborhoods, and architectural quality were also considered to be important. Planning and public policies can at least indirectly contribute to most of these attributes, through both public investments and development regulations.

Kingston, Ontario; Victoria, British Columbia, and Halifax, Nova Scotia were thought to have the most successful core areas of the 46 Canadian city centers in this size range. This paper compares these well-regarded urban core areas to nearby communities that survey respondents considered to be less successful - Brantford, Ontario; Kamloops, British Columbia; and Moncton, New Brunswick. The latter two communities had city centers that were rated about the middle of the ranking of all mid-sized urban areas included in the survey, while Brantford received the lowest ranking of any of the cities in the survey.

\subsection{Community characteristics}

Table 1 presents select demographic and socio-economic information for the six case study communities. The cities with successful core areas typically have a larger population and a lower percentage of home owners, along with higher home values. The higher rates of commuting by public transit in the urban areas with the more successful core most likely reflects the importance of the city center in terms of employment. Cities with healthy downtowns are not necessarily better off economically, at least as measured by such indicators as higher median incomes or lower unemployment rates than the comparison cities.

Table 2 compares these six city centers with respect to the characteristics associated with a successful downtown identified by Filion and colleagues [20]. Not surprisingly, the successful downtowns possess most of them. The same is also true for some of the less well-regarded core areas. Moreover, it is clear that some of the attributes (location on a body of water or designation as a provincial capital) are not readily subject to public policy interventions.

One characteristic that stands out is the greater amount of street oriented commercial frontage in the more successful city's cores. An extensive retail scene seems to be a strong indicator of downtown health. Likewise, the number of downtown hotel rooms, relative to population size, also consistently favors the more successful city in each pair. Both of these measures seem to be amenable to public policy intervention; for example zoning regulations can be used to ensure that space is reserved for retail or hotel uses. Nevertheless, the actual causal linkages are not clearly established.

The connections between specific attributes and a positive image for the city center are rather tenuous. Providing a tourist or shopper friendly environment clearly seems important. But simply 
Table 1: City profiles 2001 [21].

\begin{tabular}{lcccccc}
\hline & Halifax & Moncton & Kingston & Brantford & Victoria & Kamloops \\
\hline Population 2001 & 116,292 & 61,046 & 114,195 & 86,417 & 74,125 & 77,281 \\
Percentage of metro area & $33 \%$ & $34 \%$ & $78 \%$ & $73 \%$ & $24 \%$ & $89 \%$ \\
Increase 1996-2001 & $4.7 \%$ & $2.9 \%$ & $1.2 \%$ & $2.0 \%$ & $0.8 \%$ & $1.2 \%$ \\
Population density & $1,506 / \mathrm{km}^{2}$ & $433 / \mathrm{km}^{2}$ & $254 / \mathrm{km}^{2}$ & $1,208 / \mathrm{km}^{2}$ & $3,766 / \mathrm{km}^{2}$ & $260 / \mathrm{km}^{2}$ \\
Median age & 36.5 & 37.9 & 37.6 & 37.5 & 40.3 & 37.9 \\
Median HHincome & $\$ 38,900$ & $\$ 40,000$ & $\$ 46,000$ & $\$ 43,900$ & $\$ 34,300$ & $\$ 46,500$ \\
Unemployment rate & $7.7 \%$ & $8.2 \%$ & $7.5 \%$ & $6.8 \%$ & $8.6 \%$ & $10.1 \%$ \\
Public transit Commuters & $13.3 \%$ & $3.6 \%$ & $4.2 \%$ & $3.2 \%$ & $12.0 \%$ & $3.4 \%$ \\
Percentage homeowners & $40 \%$ & $58 \%$ & $58 \%$ & $67 \%$ & $38 \%$ & $71 \%$ \\
Average home value & $\$ 170,802$ & $\$ 101,100$ & $\$ 158,363$ & $\$ 136,482$ & $\$ 207,139$ & $\$ 152,303$ \\
\hline
\end{tabular}

Table 2: Characteristics of city centers.

\begin{tabular}{lcccccc}
\hline & Halifax & Moncton & Kingston & Brantford & Victoria & Kamloops \\
\hline Pedestrian streets & Yes & Yes & No & Yes & Yes & No \\
Block fronts of street retail & 20 & 8 & 48 & 3 & 36 & 15 \\
Tourism index & 26 & 24 & 12 & 4 & 52 & 18 \\
Provincial capital & Yes & No & No & No & Yes & No \\
Waterfront access & Limited & Extensive & Limited & Extensive & Extensive & Extensive \\
University & Yes & No & Yes & No & No & No \\
\hline
\end{tabular}

creating pedestrian streets (as in Brantford) or hotel rooms (Kamloops) is just as clearly not sufficient to achieve the desired objective. The sustainability of pedestrian friendly retail, however, depends on ensuring that the pedestrians become customers, not just passersby. The public sector can, at best, organize and regulate the setting in which the private sector activities will take place.

\section{REVITALIZATION STRATEGIES}

Table 3 lists a number of specific downtown revitalization strategies and indicates their use by the study communities. The same strategies have been widely adopted [4] by less successful city centers, emulating the features identified with more successful communities. Strategies have become ubiquitous and unique approaches that set one core area apart from the others are difficult to find.

Distressed communities typically employ more different revitalization strategies than the communities that are regarded as successful. They appear to choose any and all strategies that might contribute to core area improvement. But, at the end of the day, the results are often discouraging. No matter how many different approaches are tried or how well they are implemented, the differences in perceived quality of the city centers remain. There may be no causal connection between the public policies and core area health, or the causal connections may run in the opposite direction, with struggling city centers producing more policy initiatives. In any event, public policies may have only limited potential to effect marginal improvements. The following section describes some of the more popular revitalization strategies and assesses their potential. 
Table 3: Core area revitalization strategies.

\begin{tabular}{lccccccc}
\hline & \multicolumn{3}{c}{ Successful } & & \multicolumn{3}{c}{ Unsuccessful } \\
\cline { 2 - 3 } \cline { 7 - 8 } & Halifax & Kingston & Victoria & & Moncton & Brantford & Kamloops \\
\hline Pedestrian precinct & $\mathrm{X}$ & & $\mathrm{X}$ & & $\mathrm{X}$ & $\mathrm{X}$ & $\mathrm{X}$ \\
Parking structures & $\mathrm{X}$ & $\mathrm{X}$ & $\mathrm{X}$ & & $\mathrm{X}$ & $\mathrm{X}$ & $\mathrm{X}$ \\
Enclosed mall & $\mathrm{X}$ & & $\mathrm{X}$ & & $\mathrm{X}$ & $\mathrm{X}$ & $\mathrm{X}$ \\
Sports facilities & $\mathrm{X}$ & & & & $\mathrm{X}$ & $\mathrm{X}$ \\
Casino gambling & $\mathrm{X}$ & & Proposed & & Proposed & $\mathrm{X}$ & $\mathrm{X}$ \\
Office employment & $\mathrm{X}$ & & $\mathrm{X}$ & & $\mathrm{X}$ & $\mathrm{X}$ & $\mathrm{X}$ \\
BIA & $\mathrm{X}$ & $\mathrm{X}$ & & & $\mathrm{X}$ & $\mathrm{X}$ & $\mathrm{X}$ \\
Number of strategies & 7 & 2 & 4 & & 5 & 7 & 7 \\
\hline
\end{tabular}

\subsection{Pedestrian friendly streets}

One of the most basic strategies for a successful, sustainable downtown is the creation of attractive pedestrian streets, typically offering wide sidewalks, distinctive paving, benches, street lights, banners and flowers. These features are used to identify the city center as a special place, distinct from the rest of the city. The primary indicator of a healthy and successful downtown is an active pedestrian scene [22]. No matter how many people are attracted to a downtown, if they have no presence on the streets, the core area is unlikely to be considered a success. But if the streets in the city center have lots of pedestrian traffic, it will be taken as a sure sign that it is an interesting and vital place.

Closing streets to vehicles and other pedestrian friendly features in the city center can support street level human activity, but it may not be sufficient to ensure success. Sidewalk treatments, benches, and other street furniture provide an attractive setting in the Moncton city center, but one that attracts few users. In Kingston, the sidewalks in some parts of the city center are narrow and in poor repair, but this does little to deter their use.

\subsection{Heritage promotion and tourism}

In recent decades, many communities have 'discovered' the importance of preserving heritage properties and sites. Because city centers are often the site of original settlements, the core is likely to be the location of the largest number of historic buildings and sites. The successful core areas studied here actively promoted their heritage properties as important elements of the city center. These efforts not only provide potential tourist attractions but also help to ensure the distinctive character of the downtown, setting it off from homogenized suburban alternatives [23].

An obvious limitation of this strategy is that many communities have relatively few significant heritage sites. Moncton and Kamloops are both comparatively new cities, with few structures dating from the nineteenth century. It seems unlikely that heritage promotion strategies can make a significant contribution to revitalization efforts in such communities. Nevertheless, maintenance of the distinctive urban fabric in the core, including the street pattern and building setback lines, is likely to be an important strategy even in relatively new cities. 
Increasing tourism is also an attractive approach to downtown revitalization. This mercantilist strategy sees tourists (adopting a broad definition of tourism that includes business travelers and convention goers) [24] as contributing to the local economy through spending on accommodations, meals, and entertainment activities. Tourists are also likely to spend some of their time as pedestrians and shoppers in the city center, if there are appropriate destinations. Not surprisingly, the city centers with the best reputations are also the ones that have the most tourist activity. Halifax, Victoria, and Kingston each attract more than one million tourists annually. While tourism strategies are attractive, it seems unlikely that many communities will be able to increase tourist activity to levels comparable to these cities with successful core areas.

\subsection{Sports and entertainment centers}

Many cities have accepted the demise of the core as an employment and retail center, electing to pursue downtown revitalization that focuses on entertainment and other activities that bring people to the city center. These may include a range of entertainment options (sports venues, restaurants, casinos, theaters, night life, and cultural events) that appeal to both residents and visitors. Universities and hospitals can be considered attractions as well, for residents and nonresidents alike. Employment opportunities may also bring some local residents to the city center on a regular basis.

The limitations to this strategy in mid-sized cities are related to both scale and competition. Not every city can realistically expect to be successful in creating an entertainment environment that will attract visitors from an extensive market area [14]. The market potential for casino gambling, amusement parks, and convention centers is, after all, finite. As these markets become saturated, it will be increasingly difficult to attract visitors to locations that lack other distinctive attributes.

\subsection{Residential}

Many communities have adopted policies to increase residential uses in their city center. This is seen as a means to extend downtown activity beyond the traditional nine to five workweek, increasing both market potential and foot traffic [13, 25]. The loss of manufacturing, retail, and office activities from the core can provide opportunities for new developments or adaptive reuse of existing structures.

In the more successful city centers there are more residents than in the distressed communities (Table 4); the number of residents in all instances is relatively small, however. Economic indicators (incomes, housing values, and rents) consistently favor the more successful city in each pair. The Halifax and Kingston city centers in particular have been able to attract significant numbers of higher income households. The largely lower income residents of the core areas of Brantford and Kamloops contribute less to retail vitality.

Living in downtown may be expensive (or require costly subsidies to be affordable), however, and may produce conflicts between residents and other users, for example bars and clubs. Downtown residents also require a set of amenities that may not currently exist in the core area, including groceries, and personal service establishments. The lack of neighborhood amenities is likely to inhibit efforts to increase the downtown population. All types of residential development can not be expected to have the same positive effects on the city center. Social housing, retirement homes, and homeless shelters will make less of a contribution to city center vitality than high end condominium or loft developments. Strengthening neighborhoods adjacent to the core may be as effective a strategy as putting more housing in the city center itself. 
Table 4: Core area residential characteristics, 2001 [21].

\begin{tabular}{lcccccc}
\hline & Halifax & Moncton & Kingston & Brantford & Victoria & Kamloops \\
\hline Population & 4,004 & 1,222 & 2,965 & 1,212 & 5,956 & 1,241 \\
Change 1991-2001 & $16 \%$ & $3 \%$ & $-12 \%$ & $-7 \%$ & $25 \%$ & $33 \%$ \\
Households & 2,725 & 797 & 2,208 & 891 & 4,055 & 842 \\
Change 1991-2001 & $44 \%$ & $27 \%$ & $13 \%$ & $35 \%$ & $39 \%$ & $38 \%$ \\
Median income & $\$ 37,680$ & $\$ 23,754$ & $\$ 38,573$ & $\$ 21,458$ & $\$ 22,387$ & $\$ 21,745$ \\
As percentage of city & $98 \%$ & $59 \%$ & $116 \%$ & $49 \%$ & $65 \%$ & $47 \%$ \\
Average home value & $\$ 176,000$ & $\$ 83,700$ & $\$ 265,000$ & $\$ 96,000$ & $\$ 156,000$ & $\$ 136,000$ \\
As percentage of city & $103 \%$ & $73 \%$ & $177 \%$ & $71 \%$ & $75 \%$ & $89 \%$ \\
Average rent & $\$ 861$ & $\$ 583$ & $\$ 782$ & $\$ 532$ & $\$ 569$ & $\$ 460$ \\
As percentage of city & $126 \%$ & $104 \%$ & $121 \%$ & $86 \%$ & $84 \%$ & $71 \%$ \\
\hline
\end{tabular}

\subsection{Densification}

The decline of many central business districts has resulted in proliferation of abandoned buildings, vacant store fronts and surface parking lots, all of which contribute to a negative image of the core. The remaining viable activities and uses become isolated. Restoring the urban fabric through development regulations, design controls, and heritage preservation can help to restore continuity among key activities.

An important element of such strategies is to ensure that the area selected for concentrated development is of an appropriate size. While larger cities may be successful in expanding their concentrated downtown core areas [24, 25], this appears more difficult to accomplish in smaller cities. The success of densification based strategies is likely to depend on concentrating efforts on a compact cohesive area, one that is likely to be considerably smaller than what the city center was at its peak. It may be difficult to accept (and to accurately define) a smaller core area that is viable.

Using public improvements to define an excessively large city center is likely to dilute the effect and be counterproductive to revitalization efforts. The approach, employed by both Victoria and Brantford, dividing the core area into distinct districts, can be effective in addressing this issue. The locations of the arena in Moncton and the arena and casino in Brantford contribute little to downtown activity because they are physically separated from other downtown activities. Physical barriers, whether they are surface parking lots or rail lines, inhibit pedestrian traffic.

\subsection{Regional planning and development strategies}

The sustainability of the core area will be influenced by metropolitan development trends. Peripheral commercial development located close to highway interchanges, competes with the city center [26]. These centrifugal forces may be difficult to counter in the absence of strong regional planning or regional government [27].

Municipal consolidations have occurred in most of the case study communities, not only adding suburban development to the central city tax base but also bringing peripheral sites within the jurisdiction of a single planning authority. Municipal amalgamations have taken place in four of the urban areas within the past decade. Suburban development had been well established prior to amalgamation and continues on the periphery of even the more successful city centers. 
Consolidating multiple jurisdictions has not always eliminated competition between the downtown core and peripheral locations. An amalgamated government may, as in the case of Kingston and Halifax, locate local government offices throughout the municipality, reducing the concentration of these activities in the city center. Government restructuring where more than one significant city center previously existed may not eliminate competition between these locations. For example, the Halifax Regional Municipality continues to plan for downtown activities in the former city centers of both Halifax and Dartmouth. The City of Kamloops consciously considers the needs of the North Kamloops area in its commercial revitalization efforts and the allocation of new municipal sports facilities. In each case, public policy choices limit the ability of the downtown core to attract investment necessary to ensure its sustainability.

\section{DISCUSSION}

There are a number of factors that may actually favor sustainable downtown areas. Even those city centers that have suffered from demographic and economic decline (as well as bad planning) possess some inherently attractive aspects. The relatively small size typical of city centers in this population range provides opportunities for functional pedestrian districts with a mix of activities. Center city land values in many small and mid-sized urban areas are typically not so high (at least relative to those at the periphery) as to preclude new development. Especially in mid-sized Canadian urban areas, the availability of public (bus) transit focused on the downtown core may be an asset, but one which probably is limited to city center employees. Another advantage of the mid-sized urban core is that it is readily accessible to all areas of the region. In a market that will support only one of a particular business, a downtown location might be the most favorable.

Despite these potential advantages, not every community can aspire to a downtown that is the regional leader in terms of measures such as retail sales or employment. For many mid-sized city cores, a different metric of success will be required. Some of the factors that might be considered in designing effective strategies are described below. While there are clearly no simple answers to the problems of downtown revitalization, it is possible to identify a number of principles that seem to be applicable in a wide variety of situations.

\subsection{Perceptions matter}

The image of the core is as important as the reality. The reputation of a city and its core area is complex and unlikely to be formed based on a single attribute. There may also be a significant time lag in any change in perceptions, so that current circumstances may not adequately reflect the basis for the reputation. With this caveat in mind, there nevertheless seem to be some general observations that can be drawn from these case studies.

The initial assessment of the health of these core areas was based on a survey of urban experts from across Canada, most of whom were 'outsiders' whose image of the city centers may have been based on limited first hand experience. The way in which a community is described in the popular or professional literature, assessed by travel agents and convention planners, or how it is discussed at professional meetings will affect the external image of the community. Moreover, there is little doubt that reputation (good or bad) is likely to endure beyond the time when it accurately reflects reality.

But it is not just the city center's reputation with outsiders that matters. The way that the core area is perceived by residents of the urban area can be equally important. If the downtown is generally thought to be a place to be avoided by local residents, it seems unlikely that it will be able to have a positive image to outsiders. 


\subsection{Priorities matter}

The city center is likely to become - or remain - healthy and sustainable only if it is seen as a priority for the community. Successful city centers will rarely occur by chance. They must receive high levels of attention and investment to ensure their continued prosperity. The Trinity area in Moncton and the Southwest district in Kamloops both provide locations for new retail developments that are strongly supported by the respective municipal governments. The City of Victoria has encouraged new residential development in West Victoria across the Inner Harbor from downtown; the provincial government has relocated a number of agencies to the Selkirk waterfront area. Local residents believe that these policies have had negative impacts on the city center. Kingston on the other hand has been much more focused on the Princess Street retail core.

\subsection{Partnerships matter}

No one organization, or type of organization, can single handedly bring about the revitalization of an older urban core area. Efforts to revitalize the city center are not just the domain of the public sector. Government initiatives must be undertaken in cooperation with the private sector, civic leadership, as well as the not for profit community.

In a number of the case study communities, an active and professional Business Improvement Association (BIA) appears to be a key participant in revitalization efforts. The more effective BIAs have adopted a broad mission that may include physical and fiscal planning, research and advocacy in addition to traditional promotion and design activities. While no guarantee of success (Victoria's city center does not currently have a BIA; Moncton has one of the more effective ones), a BIA or equivalent mechanism to marshal the support of the downtown business community can make a substantial contribution to revitalization efforts.

The concept of partnerships also extends to the community broadly defined - the customers, employees, and residents who will use the city center. Developing support for downtown revitalization among these constituent groups may be difficult, but important. The implicit goal of most core revitalization efforts is a city center that is actively and visibly used. This can not be achieved without the support of the public.

\subsection{Planning matters}

Local planning efforts matter at two important levels. The first is that planning can provide the basis for articulating community goals and priorities for the city center. Basic planning functions such as visioning, strategic planning, development of alternative scenarios, coalition building, and communication are essential to the achievement of a successful revitalization program.

Professional planning also plays an important role in implementation, in activities ranging from goal setting to design review. A great deal will depend on the tactics employed in implementation. Successful core areas will be those that make the most of the assets available to them.

\subsubsection{Enclosed shopping malls}

A clear example of the importance of tactical details is provided by the enclosed shopping malls that many communities built in the 1970s and 1980s. Of the five case study cities where malls have been built, only the one in Victoria appears to be successful as a focus for revitalization efforts. The Bay Center there is well connected to the street; a number of shops are accessible from the street, rather than from the interior of the mall. The Halifax mall on the other hand is, at best, only marginally 
successful. The enclosed malls in Brantford and Kamloops are inward focused and contribute little to active street life. These malls also are plagued by high vacancy rates and the conversion of retail space to office or other uses. While Moncton has two enclosed malls at the fringe of its core area, both are highly suburbanized and separated from the core by large expanses of surface parking.

\subsubsection{Parks and open space}

Public open space is another important component of the urban fabric, particularly in the city center. But it is likely to be the quality of the open space rather than its quantity that matters most. Centennial Park in Kingston is only a small part of the downtown area but it is actively used because of the adjacent hotels, ferry docks, and marina. The resulting high level of pedestrian activity attracts vendors and people-watchers. Brantford and Kamloops, in contrast, have much more extensive waterfront park areas adjacent to their city centers, but they lack easy accessibility and programmed activities.

\subsubsection{Defining success}

Planning for city center sustainability also requires careful consideration of how success should be defined. Plans that envision a return to downtown retail dominance may be just as unrealistic as plans that feature heritage tourism in a 1950s downtown or rely on development of expensive mass transit systems. The city center is a complex economic and social space. Selecting appropriate strategies for city center revitalization efforts will depend on the primary function of the core. In each of the cities studied, the core area is more or less explicitly in competition with other parts of the city and metropolitan area for development, employment, and retail activity. For most of these functions, the city center represents only one possible location in the urban area. It will be necessary to determine the priority for development of retail, office, and residential uses in the core as opposed to other locations in the jurisdiction.

\subsubsection{Multiple markets}

The success of the city center may also depend on its ability to serve multiple markets. These markets may be defined in terms of functions (specialized retailing, entertainment, culture) or target populations (local residents, tourists, students, office workers). A core area that is able to successfully meet the needs of more than one potential market segment is more likely to be successful. While mixed users and diverse populations present the potential for conflicts, too narrow a focus on a single population or activity could limit the core's viability.

Revitalization strategies that give priority to multiple markets have the opportunity to take advantage of the complementarities between different segments. A city center that offers tourists a range of retail, dining, and entertainment opportunities may also attract locals as residents or customers. The hotels that serve tourists may make the community more attractive to conventions during a different season of the year. Similarly, student populations may provide a customer base when the tourist season ends.

\section{CONCLUSIONS}

This review of planning and revitalization efforts has identified a range of strategies and tactics that have met with varying levels of success in achieving sustainable, successful city centers. Even when similar strategies are employed, differences among communities, as well as in the actual implementation, have led to widely divergent results. Although struggling communities frequently adopt programs from municipalities with healthy city centers, the results are often indifferent levels of success. 
Few mid-sized city centers anywhere in North America are likely to achieve the recognized level of success represented by Halifax, Kingston, or Victoria. The core areas of these mid-sized Canadian cities can be expected to continue to be highly regarded. The visible signs of success - extensive pedestrian activity, a variety of retail and entertainment options, community events, and private investment - will likely sustain these city centers, allowing them to adapt to changing circumstances.

There are, however, some hopeful indications for those cities whose cores are less well regarded. Planning and public policies for the revitalization of the city centers can result in improvements to even the most distressed community. Through public investments and bringing post-secondary educational institutions to the city center, Brantford may be successful in increasing the sustainability of at least a portion of its core area. Downtown Moncton is a major employment center for the urban area, but has had limited success in extending downtown activity beyond the work day. The Kamloops city center seems to be slowly achieving its modest goals as a vital residential neighborhood. In each of these instances, the downtown core is becoming a 'finer place', one that is sustainable and better suited to the needs of community residents. And an improvement in the quality of life would seem to be an appropriate measure of success.

\section{REFERENCES}

[1] Fogelson, R., Downtown: Its Rise and Fall, 1890-1950, Yale University Press: New Haven, CT, 2001.

[2] Yeates, M., The North American City, 5th edn, Longman: New York, NY, 1988.

[3] Filion, P., Bunting, T., \& Warriner, K., The entrenchment of urban dispersion: residential preferences and location patterns in the dispersed city. Urban Studies, 36, pp. 1317-1347, 1999.

[4] Robertson, K., Can small-city downtowns remain viable? Journal of the American Planning Association, 61, pp. 429-437, 1999.

[5] Gruen, V., The Heart of Our Cities, Reinhold: New York, NY, 1964.

[6] Abbot, C., Five downtown strategies: policy discourse and downtown planning since 1945. Journal of Policy History, 5, pp. 5-27, 1993.

[7] National Main Street Center, Revitalizing Downtown, 1976-1986. National Main Street Center: Washington, DC, 1998.

[8] Teaford, J., The rough road to renaissance: urban revitalization in America 1940-1985, Johns Hopkins University Press: Baltimore, MD, 1990.

[9] Millward, H. \& Bunting, T., A tale of two CBDs II: the internal retail dynamics of downtown Halifax and downtown Kitchener. Canadian Journal of Urban Research, 8(1), pp. 1-27, 1999.

[10] Keating, D. \& Krumholz, N., Downtown plans in the 1980s: the case for more equity in the 1990s. Journal of the American Planning Association, 57, pp. 136-152, 1991.

[11] Suchman, D., Successful Infill Housing, ULI - The Urban Land Institute: Washington, DC, 2002.

[12] Turner, R. \& Rosentraub, M., Tourism, sports and the centrality of cities. Journal of Urban Affairs, 24(5), pp. 487-492, 2002.

[13] Knack, R., Downtown is where the living is easy Planning, 64, pp. 4-9, 1998.

[14] Hannigan, J., Fantasy City: Pleasure and Profit in the Postmodern Metropolis, Routledge: London, 1998.

[15] Beyard, M. et al., Developing Retail Destinations, 2nd edn, ULI - the Urban Land Institute: Washington, DC, 2001.

[16] Means, A., Downtown revitalization in small cities. Urban Land, 55(1), pp. 27-31, 56, 1997.

[17] Wells, B., Downtown Revitalization in Urban Neighborhoods and Small Cities. NortheastMidwest Institute: Washington, DC, 2000. 
[18] Palma, D., Ten myths about downtown revitalization. Main Street Renewal, ed. Roger Kemp, McFarland \& Company, Inc.: Jefferson, NC, 2000.

[19] Burayidi, M. A. (ed.), Downtowns: Revitalizing the Centers of Small Urban Communities, New York, NY: Routledge, 2001.

[20] Filion, P., Hoernig, H., Bunting, T., \& Sands, G., The successful few. Journal of the American Planning Association, 70(3), pp. 328-344, 2004.

[21] Statistics Canada. Census 2001.

[22] Lorch, B. \& Smith M., Pedestrian movement and the downtown enclosed shopping mall. Journal of the American Planning Association, 59, pp. 75-86, 1993.

[23] Birch, E., Having a longer view of downtown living. Journal of the American Planning Association, 68(1), pp. 5-21, 2002.

[24] Shaw, G. \& Williams, A., Critical Issues in Tourism, Blackwell Publishers: Oxford, 1994.

[25] Houston, L., Urban awakening. Urban Land, 57(10), pp. 34-41, 1998.

[26] Lang, R. \& LeFurgy, J., Edgeless cities. Urban Land, 63(1), pp. 40-43. 2004.

[27] Rusk, D., Cities without Suburbs, The Woodrow Wilson Center Press: Washington, DC, 1993. 